As-Syifaa Jurnal Farmasi Desember 2019; 11 (02):131-136.

ISSN : 2085-4714

\title{
PENGARUH DOSIS EKSTRAK ETANOL DAUN KAYU JAWA (Lannea coromandelic (Houtt.) Merr.) TERHADAP AKTIVITAS ANTIINFLAMASI PADA TIKUS (Rattus norvegicus).
}

\author{
Bayu Putra, Safriani Rahman \\ Fakultas Farmasi Universitas Muslim Indonesia, Makassar \\ Emai: bayu.putra@umi.ac.id
}

\begin{abstract}
In general, anti-inflammatory drugs that currently available have great side effects. One of plant that suspected have anti-inflammatory effect is Kayu Jawa (Lannea coromandelic (Houtt). Merr). Objective of this research is to determine anti-inflammatory effect and effective concentration from extract ethanol Kayu Jawa leaves. First treatment was start with rats group divided into 5 groups that initial foot volume have been measured, then $0.3 \mathrm{~mL}$ of $1 \%$ lambda carrageenan solution injected to rat's left foot as inducer, then foot volume measured again. Furthermore, rat groups were given oral induction, $1^{\text {st }}$ group were given NaCMC as control group, $2^{\text {nd }}$ group were given Diclofenac Sodium as drugs control group, then $3^{\text {rd }}, 4^{\text {th }}$, and $5^{\text {th }}$ as test group were given ethanol extract of Kayu Jawa leaves $75 \mathrm{mg} / \mathrm{kgBW}, 150 \mathrm{mg} / \mathrm{kgBW}$, and $300 \mathrm{mg} / \mathrm{kgBW}$. Foot volume measured again using plestimometer every 1 hour for 5 hours. The result showed that with $75 \mathrm{mg} / \mathrm{kgBW}, 150 \mathrm{mg} / \mathrm{kgBW}$ dan $300 \mathrm{mg} / \mathrm{kgBW}$ of ethanol extract Kayu Jawa leaves have ability to reduce rat's foots volume that induce with carrageenan. Ethanol extract of Kayu Jawa leaves with dosage $300 \mathrm{mg} / \mathrm{kgBW}$ have bigger percentage of reducing rat's foots volume (56.30\%) than the other groups.
\end{abstract}

Key words: Inflamation, kayu jawa Folium , Lannea coromandelic (Houtt.) Merr., Rat.

\section{PENDAHULUAN}

Inflamasi atau yang biasa disebut peradangan merupakan kejadian yang umum dan sering dialami oleh setiap individu. Inflamasi merupakan salah satu respon normal tubuh yang dapat disebabkan oleh cedera, trauma fisik, zat kimia yang merusak, atau zat-zat mikrobiologi. ${ }^{1} \quad$ Inflamasi yang terjadi dapat bersifat akut ataupun kronis. Inflamasi akut terjadi dalam waktu singkat yang ditujukan untuk menghilangkan agen penyebab inflamasi dan membatasi jumlah jaringan yang rusak. Sedangkan inflamasi kronik berlangsung lama dan dapat merupakan perkembangan dari inflamasi akut. $^{2,3}$

Berbagai macam obat sintetik telah dikembangkan dan dihasilkan untuk mengatasi masalah terkait inflamasi. Saat ini terdapat 2 golongan obat yang digunakan sebagai antiinflamasi yaitu golongan steroid dan nonsteroid. Kedua golongan obat antiinflamasi tersebut umumnya memiliki efek samping yang besar. Salah satu efek merugikan yang sering terjadi pada golongan obat steroid yaitu dapat menyebabkan penurunan aktivitas dari sistem imun (kekebalan) tubuh yang pada akhirnya dapat menyebabkan seseorang lebih mudah terinfeksi penyakit sedangkan golongan nonsteroid secara umum dapat menyebabkan tukak lambung dan gangguan pada ginjal. ${ }^{1}$ Oleh karena itu, diperlukan pengembangan sumber daya alam sebagai alternatif pengobatan yaitu dengan mencari dan mengidentifikasi sumber-sumber obat baru.

Salah satu tanaman yang diduga dapat memberikan efek antiinflamasi adalah 
Pengaruh dosis ekstrak etanol daun kayu jawa (Lannea coromandelic (Houtt.) Merr.) terhadap aktivitas antiinflamasi pada tikus (Rattus norvegicus).

tanaman kayu jawa (Lannea coromandelic (Houtt.) Merr.) $)^{4}$ Tanaman ini banyak tumbuh di Indonesia khusunya di Sulawesi Selatan. Biasanya, kayu jawa (Lannea coromandelic (Houtt.) Merr.) atau dalam bahasa Makassar disebut kayu tammate, bugis disebut aju jawa masih digunakan oleh masyarakat sebagai pagar dan bahan bakar dalam rumah tangga. Selain itu, secara empiris tanaman ini biasa digunakan oleh masyarakat untuk pengobatan seperti getahnya sebagai penyembuhan luka, daunnya untuk mengobati pembengkakan akibat keseleo, dan korteks kayu jawa sebagai antiinflamasi, antimitosis dan antioksidan. ${ }^{5,6,7}$

Kayu jawa (Lannea coromandelic (Houtt.) Merr.) mengandung komponen kimia berupa flavonoid, tannin dan terpenoid. ${ }^{8}$ Komponen kimia inilah yang memiliki kemungkinan dapat memberikan efek antiinflamasi dengan menghambat aktivitas enzim siklooksigenase. Penghambatan jalur siklooksigenase secara langsung akan menghambat produksi prostaglandin yang merupakan salah satu mediator untuk inflamasi. ${ }^{9,10}$ Beberapa penelitian sebelumnya telah melaporkan bahwa ekstrak metanol kulit batang Kayu Jawa memiliki aktivitas biologis seperti antibakteri, antioksidan, analgesik, aktivitas hipotensia, aktivitas penyembuhan luka. ${ }^{4}$ Singh et al. (1994) melaporkan juga bahwa ekstrak etanol kayu jawa Kayu jawa (Lannea coromandelic (Houtt.) Merr.) memiliki aktivitas antiinflamasi yang di uji cobakan pada tikus. ${ }^{11,12}$

Berdasarkan uraian diatas, maka mendasari dilakukannya pengaruh dosis ekstrak etanol daun kayu jawa (Lannea coromandelic (Houtt.) Merr.) terhadap aktivitas antiinflamasi pada tikus (Rattus norvegicus).

METODE KERJA

\section{Alat dan Bahan yang digunakan}

Alat yang dipakai yaitu seperangkat alat-alat gelas, rotavapor (Like Werke Ika RV05), sonde oral, spoit, seperangkat alat maserasi, pletysmometer (Panlab LE 7500), timbangan hewan (Berkel), timbangan analitik. Sedangkan bahan yang digunakan yaitu air suling, etanol, daun kayu jawa (Lannea coromandelic (Houtt.) Merr.), Natrium CMC, pakan hewan, natrium diklofenak, karagen, $\mathrm{NaCl}$ 0,9\%.

\section{Prosedur Kerja}

Pembuatan larutan Koloidal Natrium CMC $1 \% \mathrm{~b} / \mathrm{v}$

Natrium CMC ditimbang sebanyak 5 gram kemudian dimasukkan sedikit demi sedikit kedalam $250 \mathrm{~mL}$ air suling panas $\left(70^{\circ} \mathrm{C}\right)$ sambil diaduk dengan pengaduk elektrik hingga terbentuk larutan koloidal dan volume dicukupkan hingga $500 \mathrm{~mL}$ sambil terus diaduk sampai homogen. ${ }^{13}$

\section{Pembuatan Suspensi Natrium diklofenak $0,4167 \mathrm{mg} / \mathrm{kgbb}$}

Tablet natrium diklofenak sebanyak 10 tablet ditimbang, kemudian dihitung berat ratarata tablet dan gerus. Serbuk yang telah digerus ditimbang sebanyak 74,701 mg, kemudian disuspensikan dengan Na.CMC 1\% sedikit demi sedikit hingga homogen. Masukkan dalam labu ukur dan dicukupkan volumenya hingga $50 \mathrm{~mL}$. Suspensi Natrium diklofenak dimasukkan dalam wadah yang tertutup rapat.

\section{Pembuatan larutan karagen $1 \% \mathrm{~b} / \mathrm{v}$}

Ditimbang serbuk lamda karagen sebanyak $50 \mathrm{mg}$, kemudian dilarutkan dengan $\mathrm{NaCl}$ fisiologi sedikit demi sedikit hingga larut kemudian dicukupkan volumenya hingga 500 $\mathrm{mL}$, dimasukkan dalam wadah tertutup rapat.

\section{Pembuatan larutan uji}


Pengaruh dosis ekstrak etanol daun kayu jawa (Lannea coromandelic (Houtt.) Merr.) terhadap aktivitas antiinflamasi pada tikus (Rattus norvegicus).

Ekstrak etanol daun kayu jawa dibuat dalam 3 konsentrasi yaitu $75 \mathrm{mg} / \mathrm{kgbb}, 150$ $\mathrm{mg} / \mathrm{kgbb}$, dan $300 \mathrm{mg} / \mathrm{kgbb}$. Untuk membuat dosis $75 \mathrm{mg} / \mathrm{kgbb}$ yaitu ditimbang sebanyak $150 \mathrm{mg}$ (15 mg/200 gr tikus) kemudian di larutkan dalam $20 \mathrm{~mL}$ NaCMC $1 \% \mathrm{~b} / \mathrm{v}$ sebagai larutan stok obat. Untuk membuat dosis $150 \mathrm{mg} / \mathrm{kgbb}$ dan $300 \mathrm{mg} / \mathrm{kgbb}$ masingmasing ditimbang $300 \mathrm{mg}$ dan $600 \mathrm{mg}$ yang dilarutkan dalam $20 \mathrm{~mL} \mathrm{NaCMC} \mathrm{1 \%} \mathrm{b/v.}$

\section{Perlakuan Hewan Uji}

Hewan uji yang telah diadaptasikan diukur volume kaki awal (V0) kemudian dilakukan penginduksian inflamasi dengan cara penyuntikan larutan lamda karagen $1 \%$ pada telapak kaki kiri tikus sebanyak 0,3 mL. Penyuntikan karagen dilakukan secara intraplantar. Setelah 30 menit dilakukan pengukuran volume kaki tikus induksi (V1)

\section{HASIL PENELITIAN}

Tabel 1. Rata-rata pengukuran volume kaki tikus menggunakan pletismometer. Kemudian dilakukan pengujian dengan cara hewan uji dibagi menjadi 5 kelompok yang sebelumnya telah dipuasakan selama 8-16 jam. Hewan uji diberikan perlakuan secara oral dimana kelompok 1 sebagai kelompok kontrol yang diberi suspensi Na CMC $1 \%$ b/v, kelompok 2 sebagai kontrol pembanding yang diberi suspensi obat Natrium diklofenak $0,35 \mathrm{mg} / \mathrm{kg}$ bb, kelompok 3, 4 dan 5 sebagai kelompok uji dosis $75 \mathrm{mg} / \mathrm{kgbb}$, kelompok uji dosis 150 $\mathrm{mg} / \mathrm{kgbb}$ dan kelompok uji $300 \mathrm{mg} / \mathrm{kgbb}$. Satu jam kemudian dilakukan pengukuran volume kaki setelah penyuntikan menggunakan alat pletismometer dengan cara mencelupkan kaki kiri tikus ke dalam alat pletismometer sampai batas tanda dan dicatat. Pengukuran selanjutnya dilakukan tiap jam selama 8 jam. ${ }^{14}$

\begin{tabular}{ccccccccc}
\hline \multirow{2}{*}{ NO } & Kelompok & \multicolumn{7}{c}{ Rata-Rata Pengukuran Volume Kaki (Volume kaki \pm SD) } \\
\cline { 3 - 8 } & Perlakuan & Awal & Induksi & $\mathbf{1}$ & $\mathbf{2}$ & $\mathbf{3}$ & $\mathbf{4}$ & $\mathbf{5}$ \\
\hline 1 & Na.CMC & $0.26 \pm 0.05$ & $0.89 \pm 0.05$ & $0.92 \pm 0.04$ & $0.90 \pm 0.04$ & $0.83 \pm 0.02$ & $0.84 \pm 0.03$ & $0.80 \pm 0.03$ \\
2 & EEDKJ 75 & $0.23 \pm 0.07$ & $0.87 \pm 0.04$ & $0.74 \pm 0.03$ & $0.73 \pm 0.05$ & $0.70 \pm 0.01$ & $0.69 \pm 0.01$ & $0.66 \pm 0.04$ \\
3 & EEDKJ 150 & $0.29 \pm 0.02$ & $1.04 \pm 0.09$ & $0.93 \pm 0.03$ & $0.82 \pm 0.04$ & $0.71 \pm 0.02$ & $0.67 \pm 0.03$ & $0.64 \pm 0.00$ \\
4 & EEDKJ 300 & $0.30 \pm 0.03$ & $1.16 \pm 0.31$ & $0.90 \pm 0.13$ & $0.82 \pm 0.08$ & $0.63 \pm 0.05$ & $0.53 \pm 0.02$ & $0.49 \pm 0.03$ \\
5 & Na. Diclofenak & $0.27 \pm 0.01$ & $1.02 \pm 0.05$ & $0.73 \pm 0.04$ & $0.67 \pm 0.01$ & $0.55 \pm 0.02$ & $0.42 \pm 0.03$ & $0.36 \pm 0.03$ \\
\hline
\end{tabular}

Ket. EEDKJ : ekstrak etanol daun kayu jawa

Tabel 2. Rata-rata persen penurunan volume kaki tikus

\begin{tabular}{ccc}
\hline No & Kelompok perlakuan & Rata-rata persen penurunan (\%) \\
\hline 1 & Na.CMC & 9.45 \\
2 & EEDKJ 75 & 23.64 \\
3 & EEDKJ 150 & 38.25 \\
4 & EEDKJ 300 & 56.30 \\
5 & Na. diklofenak & 64.52 \\
\hline
\end{tabular}

\section{PEMBAHASAN}

Pada penelitian ini telah dilakukan uji pengaruh dosis ekstrak etanol daun kayu jawa
(Lannea coromandelic (Houtt.) Merr.) terhadap aktivitas antiinflamasi pada tikus (Rattus norvegicus). Penentuan potensi antiinflamasi 
Pengaruh dosis ekstrak etanol daun kayu jawa (Lannea coromandelic (Houtt.) Merr.) terhadap aktivitas antiinflamasi pada tikus (Rattus norvegicus).

ekstrak etanol daun kayu jawa dilakukan dengan cara mengukur volume kaki hewan coba yang diinduksi menggunakan lamda karagen. Pengukuran volume kaki hewan coba menggunakan alat pletismometer. Prinsip pengukuran alat tersebut berdasarkan hukum Archimedes yaitu benda yang dimasukkan ke dalam zat cair akan memberi gaya atau tekanan ke atas sebesar volume yang dipindahkan. Metode ini lebih sederhana, cepat, dan hasil pengukuran yang didapatkan lebih akurat dibandingkan dengan alat yang lain.

Sampel yang digunakan dalam penelitian ini adalah ekstrak etanol daun kayu jawa (EEDKJ). Ekstrak etanol diperoleh melalui proses maserasi dengan menggunakan pelarut etanol $70 \%$. Untuk melihat kemampuan EEDKJ sebagai antiinflamasi, maka diujikan pada hewan coba tikus. Hewan uji dibagi kedalam 5 kelompok yang terdiri dari kelompok kontrol (diberikan Na.CMC 1\%), kelompok perlakuan (EEDKJ dosis $75 \mathrm{mg} / \mathrm{kgBB}, 150 \mathrm{mg} / \mathrm{kgBB}$, dan 300 $\mathrm{mg} / \mathrm{kgBB}$ ), dan kelompok pembanding (Natrium Diklofenak). Sebelum perlakuan tikus diinduksi dengan lamda karagen $1 \%$ secara intraplantar.

Pada tabel 1 memperlihatkan ratarata penurunan volume kaki tikus setelah diinduksi lamda karagen. Pada tabel tersebut menunjukkan bahwa semua kelompok memperlihatkan penurunan volume kaki pada tiap jam. Rata-rata penurunan volume kaki pada semua kelompok uji mengalami perubahan mulai jam 1 hingga jam ke 5. Untuk melihat besarnya potensi antiinflamasi tiap kelompok maka data pada tabel 1 dihitung persen penurunan yang dapat dilihat pada tabel 2.
Berdasarkan tabel 2 di atas, dapat dilihat bahwa kelompok perlakuan EEDKJ memperlihatkan adanya penurunan volume kaki tikus yang sangat baik jika dibandingkan dengan kelompok kontrol (Na.CMC) yaitu 23,64 - 56,30\%, namun EEDKJ dosis 300 $\mathrm{mg} / \mathrm{kgBB}$ memberikan persen penurunan yang lebih besar jika dibandingkan dengan 2 varian dosis EEDKJ lainnya. Sedangkan kelompok kontrol (Na.CMC) mengalami rata-rata persentase penurunan volume kaki sebesar $9,45 \%$.

Untuk melihat perbedaan antar kelompok perlakuan pada tabel 2, maka dilakukan uji statistik dengan menggunakan one way anova. Sebelum melakukan uji tersebut, terlebih dahulu dilakukan uji kenormalan data. Hasil menunjukkan bahwa data pada penelitian ini terdistribusi normal dengan nilai $p>0,005$. Berdasarkan hasil tersebut, pengujian statistik dilanjutkan dengan uji one way anova yang menunjukkan adanya perbedaan yang nyata $(P<0,05)$ (data dapat dilihat pada lampiran 2). Hal ini berarti terdapat perbedaan penurunan volume kaki tikus yang dihasilkan oleh tiap kelompok perlakuan. Oleh karena itu, dilakukan analisis lanjutan yaitu dengan uji post hoc menggunakan LSD (data dapat dilhat pada lampiran 2). Data tersebut menunjukkan bahwa kelompok EEDKJ dosis $75 \mathrm{mg} / \mathrm{kgBB}$ dan $150 \mathrm{mg} / \mathrm{kgBB}$ berbeda nyata dengan kelompok yang lain. Hal ini berarti EEDKJ 75 $\mathrm{mg} / \mathrm{kgBB}$ dan $150 \mathrm{mg} / \mathrm{kgBB}$ memiliki aktivitas yang berbeda dengan kelompok lainnya dalam hal penurunan volume kaki. Kelompok perlakuan EEDKJ dosis $300 \mathrm{mg} / \mathrm{kgBB}$ berbeda nyata dengan kelompok kontrol (Na.CMC), EEDKJ dosis $75 \mathrm{mg} / \mathrm{kgBB}$, dan EEDKJ dosis $150 \mathrm{mg} / \mathrm{kgBB}$, tetapi tidak berbeda nyata 
Pengaruh dosis ekstrak etanol daun kayu jawa (Lannea coromandelic (Houtt.) Merr.) terhadap aktivitas antiinflamasi pada tikus (Rattus norvegicus).

dengan pembanding (Na.diklofenak). Hal ini berarti bahwa kelompok EEDKJ dosis 300 $\mathrm{mg} / \mathrm{kgBB}$ memiliki efek yang berbeda dengan EEDKJ dosis $75 \mathrm{mg} / \mathrm{kgBB}$, EEDKJ dosis 300 $\mathrm{mg} / \mathrm{kgBB}$, dan kontrol (Na.CMC) dalam hal penurunan volume kaki, tetapi memiliki efek yang sama dengan pembanding (Na.diklofenak).

Pada penelitian ini, semua kelompok perlakuan EEDKJ berpotensi menurunkan pembengkakan kaki hewan coba (antiinflamasi). Hal ini dikarenakan adanya beberapa kandungan kimia seperti glikosida, flavonoid, dan steroid-triterpenoid. ${ }^{8}$ Kandungan kimia flavonoid dan steroid triterpenoid diduga dapat memberikan efek penurun bengkak atau udema. Mekanisme kerja dari flavonoid dalam menurunkan bengkak atau bersifat antiinflamasi yaitu melancarkan peredaran darah ke seluruh tubuh dan mencegah terjadinya penyumbatan pada pembuluh darah, mengandung antiinflamasi, juga berfungsi sebagai antioksidan, dan membantu mengurangi rasa sakit jika terjadi pendarahan atau pembengkakan. ${ }^{15}$

Selain itu, flavanoid dapat menghambat produksi nitrit oksida dengan menghambat ekspresi iNOS yang nantinya mempengaruhi radikal bebas. Studi terbaru melaporkan bahwa flavanoid memiliki mekanisme menghambat enzim penghasil eicosanoid termasuk fosfolipase A2, siklooksigenase, dan lipoksigenase, sehingga mengurangi konsentrasi prostanoid dan leukotrien. Terutama turunan flavon yang berfungsi mengekspresikan aktivitas antiinflamasi dengan modulasi ekspresi gen proinflamasi seperti siklooksigenase-2, oksida nitrat yang dapat diinduksi dari beberapa sitokin penting. ${ }^{16,17}$

\section{KESIMPULAN}

Dari hasil penelitian menunjukkan bahwa semua kelompok pengujian ekstrak etanol daun kayu jawa dengan dosis 75 $\mathrm{mg} / \mathrm{kgBB}, 150 \mathrm{mg} / \mathrm{kgBB}$, dan $300 \mathrm{mg} / \mathrm{kgBB}$ memiliki potensi sebagai antiinflamasi pada tikus dan dosis $300 \mathrm{mg} / \mathrm{kgBB}$ memiliki efek yang paling baik dalam menurunkan pembengkakan kaki tikus serta memiliki nilai statistik tidak berbeda nyata dengan kelompok pembanding (Natrium Diklofenak).

\section{UCAPAN TERIMA KASIH}

Penulis mengucapkan terima kasih kepada Lembaga Penelitian dan Pengembangan Sumberdaya (LP2S) Universitas Muslim Indonesia (UMI) Makassar yang telah memfasilitasi selama pelaksanaan penelitian sampai terpenuhinya luaran penelitian.

\section{DAFTAR PUSTAKA}

1. Harvey RA, Champe PC. Farmakologi Ulasan Bergambar 4 nd ed. China: Lippincott William\& Wilkins,2009.

2. Kumar V, Cotran RS, Robbins SL. Buku Ajar Patologi 8 nd ed. Jakarta: Penerbit Buku Kedokteran EGC,2009.

3. Katzung BG. Farmakologi Dasar dan Klinik. Jakarta: Salemba Medika, 2004.

4. Alam MB, Kwon KR, Lee SH, Lee SH. Lannea coromandelica (Houtt.) Merr. Induces Heme Oxygenase 1 (HO-1) Expression and Reduces Oxidative Stress via the p38/c-Jun N-Terminal KinaseNuclear Factor Erythroid 2-Related Factor 2 (p38/JNK-NRF2)-Mediated Antioxidant Pathway. Int J Mol Sci.2017;18(2):266284.

5. Rahayu M, Sunarti S, Sulistiarini D, Prawiroatmodjo S. Pemanfaatan Tumbuhan Obat Secara Tradisional Oleh Masyarakat Lokal di Pulau Wawonii, Sulawesi Tenggara. Biodiversitas.2006;7(3):245-250. 
Pengaruh dosis ekstrak etanol daun kayu jawa (Lannea coromandelic (Houtt.) Merr.) terhadap aktivitas antiinflamasi pada tikus (Rattus norvegicus).

6. Rahmadani F. Uji Aktivitas Antibakteri Dari Ekstrak Etanol 96\% Kulit Batang Kayu Jawa (Lannea coromandelica) Terhadap Bakteri Staphylococcus aureus, Escherichia coli, Helicobacter pylori, Pseudomonas aeruginosa (Skripsi). Jakarta: Fakultas Kedokteran Dan IImu Kesehatan. UIN Syarif Hidayatullah, 2015.

7. Saputra A. Uji Aktivitas Antiinflamasi Ekstrak Etanol $96 \%$ Kulit Batang Kayu Jawa (Lannea coromandelica) dengan Metode Stabilitas Membrane Sel Darah Merah Secara In Vitro (Skripsi). Jakarta: Fakultas Kedokteran Dan IImu Kesehatan. UIN Syarif Hidayatullah, 2015.

8. Manik MA, Wahid SMA, Islam A, Pal KT, Ahmed. A Comparative Study of the Antioxidant, Antimicrobial and Thrombolytic Activity of the Bark and Leaves of Lannea coromandelica (Anacardiaceae). International Journal of Pharmaceutical Sciences and Research. 2013;4(7): 2609-2614.

9. Nijveldt RJ, Van Nood E, Van Hoorn DE, Boelens PG, Van Norren K, Van Leeuwen PA. Flavonoids: A Review Of Probable Mechanisms Of Action And Potential Applications. Am J Clin Nutr.2001;74(4):418-25.

10. Robak J, Gryglewski RJ. Bioactivity of Flavonoids. Pol J Pharmacol. 1996;48(6):555-64.
11. Singh S, Singh G. Anti-inflammatory activity of Lannea coromandelica Bark Extract in Rats. Phytother Res.1994;8:311-313.

12. Singh S, Singh G. Hypotensive Activity of Lannea coromandelica Bark Extract. Phytother Res. 1996;10:429-430.

13. Parrott EL. Pharmaceutical Technology Fundamental Pharmaceutics 3nd. Mineapolis: Ed. Burgess Publishing Company, 1971.

14. Narande JM, Wulur A, Yudistira A. Uji efek Antiinflamasi Ekstrak Etanol Daun Suji (Dracaena Angustifolia Roxb) Terhadap Edema Kaki Tikus Putih Jantan Galur Wistar. Pharmacon J IIm Farm Unsrat. 2013;2(3):14-18.

15. Wahyuningsih S. Soemardji AA, Febiyanti D. Efek Gel Lidah Buaya (Aloe barbadensis Mill ) Terhadap Penyembuhan Luka Bakar Eksperimen Pada Tikus Wistar Betina. Prosiding seminar nasional tumbuhan obat indonesia XXIX. 2006:73-81.

16. Kim HP, Son KH, Chang HW, Kang SS. Anti-inflammatory Plant Flavonoids And Cellular Action Mechanisms. J Pharmacol Sci.2004;96(3):229-45.

17. Serafini M, Peluso I, Raguzzini A. Flavonoids as Anti-Inflammatory Agents. Proc Nutr Soc.2010;69(3):273-8. 